\title{
Time from Symptom Debut to Dementia Assessment by the Specialist Healthcare Service in Norway
}

\author{
Anne-Sofie Helvik ${ }^{a-c}$ Knut Engedalc Jūratè Šaltytè Benth ${ }^{d-f}$ \\ Geir Selbæk ${ }^{c, f, g}$ \\ ${ }^{a}$ General Practice Research Unit, Department of Public Health and Nursing, Faculty of \\ Medicine and Health Sciences, Norwegian University of Science and Technology (NTNU), \\ Trondheim, Norway; ${ }^{b}$ St Olavs University Hospital, Trondheim, Norway; ${ }^{c}$ Norwegian \\ National Advisory Unit on Ageing and Health, Vestfold Health Trust, Tønsberg, Norway; \\ ${ }^{d}$ Institute of Clinical Medicine, Campus Ahus, University of Oslo, Oslo, Norway; ${ }^{\text {H }}$ Ø囚KH, \\ Research Centre, Akershus University Hospital, Lørenskog, Norway; ${ }^{\mathrm{f} C e n t r e ~ f o r ~ O l d ~ A g e ~}$ \\ Psychiatric Research, Innlandet Hospital Trust, Ottestad, Norway; ${ }^{9}$ Institute of Health and \\ Society, Faculty of Medicine, University of Oslo, Oslo, Norway
}

\section{Keywords}

Dementia · Delayed diagnosis · Neuropsychiatric symptoms · Next of kin · Memory clinic - Minimal cognitive impairment - Older people - Subjective cognitive complaints . Socioeconomic status $\cdot$ Timely diagnosis

\section{Abstract}

Objectives: We described the duration from symptom debut to assessment at specialist healthcare outpatient clinics for dementia in Norway and explored whether educational level was associated with time from symptom debut to dementia assessment. Methods: The study comprised 835 persons from a register for individuals with cognitive symptoms (NorCog). The outcome variable was time in months from symptom debut to assessment. The main independent variable was the number of years of education. Also age, gender, marital status, cognitive function, neuropsychiatric symptoms, assistance and location were assessed. Results: In an adjusted linear mixed model, a higher educational level was associated with a longer duration from symptom debut to assessment, where 5 additional years of education increased the time from symptom debut to consultation by $10 \%$. Conclusion: The findings may perhaps be explained by the hypothesis that highly educated people may be able to compensate better for cognitive impairment, which is in line with a hypothesis of cognitive reserve. 
Helvik et al:: Time from Symptom Debut to Dementia Assessment by the Specialist Healthcare Service in Norway

\section{Introduction}

An estimated 10-11 million people in Europe aged 60 years or older have dementia [1], a prevalence that is expected to increase as the number of older individuals grows over the years to come. In Norway, an estimated 78,000 persons have dementia [2]. Dementia is caused by various brain disorders and is in most cases progressive. It is characterized by impaired function in activities related to daily living and cognition and changes in psychological, behavioural and social function [3]. Even so, some people are able to function quite well despite their brain pathology in their early stage of dementia. It is found that some have a higher cognitive reserve capacity than others because of the structural and functional features of their brain [4-7], which may be linked to higher education [6, 7]. Older persons with signs of dementia in Norway may be assessed by primary care physicians but are also referred to specialist care, in most cases geriatric or geriatric psychiatry outpatient clinics. Many, in particular older individuals, with significant symptoms of dementia may remain undiagnosed [8-11].

In most western countries, next of kin has an important role in the decision to seek a diagnostic assessment for a person with suspected dementia [12-14]. However, in many cases, neither the person themselves nor the next of kin are aware of early signs of dementia. Observed changes in cognition may be interpreted as normal aging rather than the onset of cognitive decline due to dementia [10,12, 15-17]. Lower educational levels and a lack of knowledge on dementia symptoms may contribute to difficulty recognizing symptoms of dementia [16], delaying a visit to the family physician or outpatient specialist clinic for an assessment $[10,17,18]$. Furthermore, stigmata related to mental health diseases may delay a consultation $[17,19,20]$.

A timely diagnosis helps to exclude non-dementia disorders (i.e., depression) in a timely manner and allows people to plan for the future [21], to receive treatment to reduce cognitive and neuropsychiatric symptoms [22,23] and to have access to in-home care and social interventions. Timely diagnosis may also help the family or next of kin to reduce the burden of care and delay admission to a nursing home [24]. Studies have found that the mean duration from onset of dementia-related symptoms until assessment or diagnosis at an outpatient specialist clinic is about 1-2 years [12-14, 18, 25-27]. Some studies have reported a longer mean duration $[28,29]$. In Norway, a small study $(n=69)$ found that the mean duration between the onset of dementia-related symptoms to referral in individuals younger than 65 years was 1.5 years for individuals subsequently diagnosed with dementia related to Alzheimer disease, while it was 2 years in those with frontotemporal dementia [30].

In general, older individuals with a shorter education have a higher barrier towards seeking medical help [15, 31-33]. A recent Chinese study found that a longer duration from the onset of symptoms of dementia to assessment at a memory clinic was associated with a lower educational level [18]. However, one European study reported that for people with symptoms of dementia and normal physical function, higher age, female gender and poorer cognitive function were associated with a longer duration until assessment at a memory clinic, but this was not associated with educational level [34]. Others have reported that the mean duration to assessment and diagnosis is longer in younger individuals ( $<65$ years) than in older individuals ( $\geq 65$ years) [29]. Furthermore, behavioural and personality changes can delay the decision to seek help [29, 30,35]. Nevertheless, more severe symptoms or a combination of symptoms normally trigger the decision to seek help [15, 36, 37].

The aim of the present study was to describe the duration from symptom debut to assessment at Norwegian outpatient specialist healthcare clinics for dementia and to explore whether educational level was associated with the duration from symptom debut to assessment when adjusting for sociodemographic factors, cognitive functioning, neuropsychiatric symptoms and outpatient clinic location and type. 
Helvik et al:: Time from Symptom Debut to Dementia Assessment by the Specialist Healthcare Service in Norway

\section{Methods}

This cross-sectional study was based on information from the Norwegian register for individuals with cognitive symptoms who have been assessed by a specialist healthcare service (NorCog) between February 2014 and July 2016. The individuals in the study were from 3 of the country's 4 healthcare service regions. Examinations were standardized and consisted of an interview with the individual and a next of kin, an evaluation and testing of cognitive function, and a psychiatric and physical examination of the individual, including a preliminary neurological examination [38]. In addition, study participants had blood sample analyses, a magnetic resonance imaging scan, single-photon emission computed tomography in the case of suspected Parkinson-plus syndromes or frontotemporal dementia, and spinal fluid testing for individuals with vague symptoms [38]. All individuals in NorCog have consented to allow information from the diagnostic assessment to be stored until 2030 and to be used for research. The Norwegian Data Inspectorate has approved all data collection and storage by NorCog. The present study was approved by the Regional Committee for Medical and Health Research Ethics South East in Norway (REK) (2016/1117) and the NorCog steering committee.

\section{Participants}

In total, 1,721 individuals were registered in NorCog from February 2014 to July 2016. Information on the duration from symptom debut to assessment was available for 886 of them, but information regarding the level of education was missing for 52 . Thus, 835 (48.6\% of the total) individuals were included in the present study.

\section{Measures}

Time from Symptom Debut to Assessment. Next of kin reported the number of months that had passed since the individual in question first experienced symptoms related to cognitive impairment.

Demographic Information. Demographic information, including years of education, age, gender and marital status, was collected as part of the separate interviews with the individual and their next of kin.

Cognitive Function. Cognitive function was assessed using several cognitive tests [38]. We used results from the Mini-Mental State Examination, Norwegian version (MMSE-NR) [39]. The MMSE has been translated, adapted and validated for Norwegian conditions [40].

Neuropsychiatric Symptoms. Neuropsychiatric symptoms were evaluated using the Neuropsychiatric Inventory Questionnaire (NPI-Q) [41], translated to Norwegian [42]. The 10 -item version was used in the analysis. It covers the following symptoms: delusion, hallucination, euphoria, agitation/aggression, disinhibition, irritability/lability, depression/ dysphoria, anxiety, apathy/indifference, and aberrant motor behaviour. Next of kin rated the severity of each symptom based on its occurrence in the previous 4 weeks. Three subsyndromes of the NPI have been identified based on community-living individuals in Norway [43]. They are termed "agitation," "psychosis," and "affective symptoms." "Agitation" comprises agitation/aggression, euphoria, disinhibition, aberrant motor behaviour and irritability; "psychosis" comprises delusions and hallucinations, while "affective symptoms" cover depression, anxiety and apathy.

Diagnostic Procedure. The diagnosis was based on the International Classification of Diseases 10th Revision (ICD-10) and was set by the clinicians at each clinic after the described assessment procedure [38].

Receiving Domiciliary Care (Yes/No). This item was recorded based on information from the individuals with dementia-related symptoms or next of kin. 
Helvik et al.: Time from Symptom Debut to Dementia Assessment by the Specialist Healthcare Service in Norway

Table 1. Sample characteristics

\begin{tabular}{|c|c|c|c|}
\hline & Health region I & Health region II & Health region III \\
\hline \multicolumn{4}{|l|}{ Outpatient clinic } \\
\hline Participants, $n$ & 468 & 136 & 231 \\
\hline Geriatric clinic, $n(\%)$ & $323(69.0)$ & $63(46.3)$ & $231(100)$ \\
\hline \multicolumn{4}{|l|}{ Individual information } \\
\hline Mean age (SD), years & $74.1(9.9)$ & $77.1(7.9)$ & $79.4(7.0)$ \\
\hline Women, $n(\%)$ & 257 (54.9) & $83(61.0)$ & $124(53.7)$ \\
\hline Mean education (SD), years & $11.6(3.5)$ & $10.0(2.9)$ & $10.1(3.1)$ \\
\hline Single $^{\mathrm{a}}, n(\%)$ & $186(40.6)$ & $62(45.9)$ & $86(40.8)$ \\
\hline Receiving domiciliary care ${ }^{\mathrm{b}}, n(\%)$ & $307(66.6)$ & $83(62.9)$ & $111(48.7)$ \\
\hline Mean MMSE-NR ${ }^{c}(S D)$ & $24.0(4.6)$ & $22.9(4.3)$ & $21.2(4.8)$ \\
\hline \multicolumn{4}{|l|}{ Time from symptom to consultation } \\
\hline Mean (SD) & $32.8(40.1)$ & $31.6(39.4)$ & $37.7(55.2)$ \\
\hline Median (min., max.) & $24.0(0,580)$ & $24.0(1,396)$ & $24.0(3,744)$ \\
\hline Mean NPI-Q Agitation ${ }^{\mathrm{d}}$ (SD) & $1.7(2.3)$ & $1.6(2.0)$ & $1.4(2.0)$ \\
\hline Mean NPI-Q Psychosise (SD) & $0.6(1.2)$ & $0.6(1.2)$ & $0.6(1.2)$ \\
\hline Mean NPI-Q Affective ${ }^{\mathrm{f}}$ (SD) & $2.4(2.2)$ & $2.4(2.0)$ & $2.1(1.9)$ \\
\hline \multicolumn{4}{|l|}{ Diagnoses, $n(\%)$} \\
\hline SCI & $43(9.5)$ & $2(1.5)$ & $24(12.2)$ \\
\hline MCI & $151(33.5)$ & $52(40.0)$ & 25 (12.7) \\
\hline Dementia & $240(53.2)$ & $71(54.6)$ & $147(74.6)$ \\
\hline Others ${ }^{\mathrm{g}}$ & $17(3.8)$ & $5(3.8)$ & $1(0.5)$ \\
\hline
\end{tabular}

SD, standard deviation; MMSE-NR, sum score of the Mini-Mental State Examination, Norwegian revised version; NPI-Q, Neuropsychiatric Inventory Questionnaire; SCI, subjective cognitive impairment; MCI, mild cognitive impairment. ${ }^{a}$ Marital status, 31 missing values. ${ }^{\mathrm{b}} 14$ missing values. ${ }^{\mathrm{c}} 4$ missing values. ${ }^{\mathrm{d}} 19$ missing values (after imputation). ${ }^{\mathrm{e}} 18$ missing values (after imputation). ${ }^{\mathrm{f}} 19$ missing values (after imputation). ${ }^{\mathrm{g}}$ Other diagnoses include depression, anxiety and psychotic diseases.

Location of Clinic. The geographical location of the outpatient specialist healthcare clinic was recorded, and information was grouped according to which of the 3 healthcare service regions the clinic was a part of, in this case either the South East (I), Western (II) or Middle (III) region of Norway. There is no organisational difference between these 3 healthcare regions. Furthermore, we also recorded the type of the outpatient healthcare clinic the individuals went to, i.e., geriatric versus a geriatric psychiatric outpatient clinic.

\section{Analysis}

The sample characteristics were presented as means and standard deviations (SD) or frequencies and percentages. Those included and excluded from the present study were compared using a linear mixed model for continuous variables and a generalized linear model for categorical variables. All models included a fixed effect for the variable whether people with dementia-related symptoms were included or not, and random effects for centre to adjust for possible intra-centre correlations. To assess the association between duration from symptom debut to assessment and years of education, a similar linear mixed model was estimated with a random effect for centre. Since the outcome variable was highly skewed, ln-transformation was applied prior to analyses. A bivariate model with fixed effects for years of education was estimated. A number of bivariate models for adjustment variables were then estimated. Interactions between years of education and adjustment variables were assessed but were excluded if not significant. Finally, a multivariate model was estimated.

All statistical analyses were performed in SPSS version 24 or SAS version 9.4. Results with $p$ values $<0.05$ were considered statistically significant. 
Table 2. Comparison of individual information for individuals who were and were not included

\begin{tabular}{llcc}
\hline & $\begin{array}{l}\text { Included } \\
(n=835)\end{array}$ & $\begin{array}{l}\text { Not included } \\
(n=886)\end{array}$ & $p$ value \\
\hline Mean age (SD), years & $76.1(9.1)$ & $73.0(10.0)$ & 0.001 \\
Women, $n$ (\%) & $463(55.6)$ & $469(52.9)$ & 0.213 \\
Mean education (SD), years & $10.9(3.4)$ & $11.5(3.6)$ & 0.373 \\
Single, $n$ (\%) & $313(38.9)$ & $337(40.6)$ & 0.482 \\
Receiving domiciliary care, $n$ (\%) & $319(38.9)$ & $255(30.6)$ & 0.013 \\
Mean MMSE-NR (SD) & $23.1(4.8)$ & $24.1(4.5)$ & 0.026 \\
Mean time from symptom to consultation (SD), months & $33.9(44.7)$ & $29.4(21.7)$ & 0.472 \\
Mean NPI-Q Agitation (SD) & $1.6(2.2)$ & $1.6(2.2)$ & 0.913 \\
Mean NPI-Q Psychosis (SD) & $0.6(1.2)$ & $0.5(1.1)$ & 0.333 \\
Mean NPI-Q Affective (SD) & $2.3(2.1)$ & $2.1(2.2)$ & 0.093 \\
\hline
\end{tabular}

SD, standard deviation; MMSE-NR, sum score of the Mini-Mental State Examination, Norwegian revised version; NPI-Q, Neuropsychiatric Inventory Questionnaire.

\section{Results}

Of the 835 individuals with dementia-related symptoms included in our study, 468 (56\%) came from the southeast part of Norway, which includes the capital of Oslo (health region 1). Six hundred and seventeen individuals (73.9\%) were examined in a geriatric outpatient clinic (Table 1). The mean age of the total sample was 76.0 (SD 9.1, range 36-95) years; 464 (55.6\%) patients were women. The mean score of the MMSE-NR was 23.1 (SD 4.8). In total, 69 (8\%) individuals were diagnosed with subjective cognitive impairment, 228 (27\%) with mild cognitive impairment (MCI) and 458 (55\%) with dementia. Among those with dementia, 310 were diagnosed with Alzheimer disease, 61 with unspecified dementia, 55 with vascular dementia and 32 with dementia associated with other diseases. Of the 32 individuals diagnosed with dementia associated with other diseases, 16 were diagnosed with Lewy body dementia, 13 with Parkinson-related dementia, and 3 with frontotemporal dementia. We did not have information on the diagnosis for 57 (7\%) people, while $23(3 \%)$ were diagnosed with other psychiatric diseases, including depression, anxiety and psychotic diseases.

The group excluded from the analyses had a similar gender distribution but was younger (mean 73.0 [SD 10.0] years) and had better cognitive function (mean score of MMSE-NR 24.1 [SD 4.5]), and fewer received domiciliary care (255 individuals [30.6\%] vs. 319 individuals [38.9\%]) (Table 2).

\section{Time from Symptom Debut to Assessment}

The median time from symptom debut to assessment was 24.0 (min. 0, max. 744) months. In an unadjusted analysis, the variable "years of education" was not associated with time from symptom debut to assessment. No significant interactions were identified. In an adjusted analysis, both longer education and a higher agitation sub-syndrome score on the NPI-Q were associated with a longer duration from symptom debut to assessment (Table 3). The model also included the degree of cognitive functioning, demographic information (age, gender and marital status), information on whether or not the individual received domiciliary care (yes/ no), type of specialist outpatient clinic and health region as well as the diagnosis received. Compared to those diagnosed with dementia, those diagnosed with $\mathrm{MCI}$ had a significantly shorter duration from onset of symptoms to assessment. 
Table 3. Outcome variable ln of "time from symptom to assessment" ( $n=722)$ after excluding cases with at least 1 missing value

\begin{tabular}{|c|c|c|c|c|c|}
\hline & \multirow[t]{2}{*}{$N$} & \multicolumn{2}{|c|}{ Unadjusted model } & \multicolumn{2}{|l|}{ Adjusted model } \\
\hline & & coefficient (SE) & $p$ value & coefficient (SE) & $p$ value \\
\hline Education, years & 722 & $0.02(0.01)$ & 0.088 & $0.02(0.01)$ & 0.011 \\
\hline \multicolumn{6}{|l|}{ Outpatient centre } \\
\hline \multicolumn{6}{|l|}{ Health region } \\
\hline I - ref. & 422 & 0 & & 0 & \\
\hline II & 124 & $-0.09(0.10)$ & 0.368 & $-0.06(0.12)$ & 0.697 \\
\hline III & 176 & $0.12(0.12)$ & 0.382 & $0.11(0.16)$ & 0.540 \\
\hline \multicolumn{6}{|l|}{ Clinics } \\
\hline Geriatric - ref. & 532 & 0 & & 0 & \\
\hline Psychiatry & 190 & $-0.06(0.09)$ & 0.520 & $-0.01(0.11)$ & 0.896 \\
\hline \multicolumn{6}{|l|}{ Individual information } \\
\hline Age, years & 722 & $-0.002(0.004)$ & 0.521 & $-0.01(0.004)$ & 0.084 \\
\hline \multicolumn{6}{|l|}{ Gender } \\
\hline Men - ref. & 325 & 0 & & 0 & \\
\hline Women & 397 & $0.001(0.06)$ & 0.988 & $-0.02(0.07)$ & 0.754 \\
\hline \multicolumn{6}{|l|}{ Marital status } \\
\hline Non-single - ref. & 428 & 0 & & 0 & \\
\hline Single & 294 & $0.02(0.06)$ & 0.771 & $0.004(0.07)$ & 0.953 \\
\hline \multicolumn{6}{|l|}{ Receiving domiciliary care } \\
\hline No - ref. & 454 & 0 & & 0 & \\
\hline Yes & 268 & $0.11(0.06)$ & 0.095 & $0.10(0.07)$ & 0.187 \\
\hline MMSE-NR & 722 & $-0.02(0.007)$ & 0.011 & $-0.01(0.008)$ & 0.186 \\
\hline Agitation & 722 & $0.05(0.01)$ & $<0.001$ & $0.04(0.02)$ & 0.011 \\
\hline Psychosis & 722 & $0.01(0.03)$ & 0.606 & $-0.05(0.03)$ & 0.076 \\
\hline Affective & 722 & $0.04(0.01)$ & 0.005 & $0.02(0.02)$ & 0.230 \\
\hline \multicolumn{6}{|l|}{ Diagnoses } \\
\hline SCI & 60 & $-0.23(0.11)$ & 0.042 & $-0.23(0.12)$ & 0.063 \\
\hline MCI & 218 & $-0.28(0.07)$ & $<0.001$ & $-0.23(0.08)$ & 0.004 \\
\hline Other & 22 & $-0.25(0.18)$ & 0.167 & $-0.26(0.18)$ & 0.152 \\
\hline Dementia - ref. & 422 & 0 & & 0 & \\
\hline \multicolumn{6}{|l|}{ Education, years $\times$ Health region } \\
\hline II & & & 0.553 & & \\
\hline III & & & 0.785 & & \\
\hline \multicolumn{6}{|l|}{ Education, years $\times$ Clinics } \\
\hline \multicolumn{6}{|l|}{ Geriatric-ref. } \\
\hline Psychiatry & & & 0.830 & & \\
\hline Education, years $\times$ Age & & & 0.879 & & \\
\hline Education, years $\times$ Gender & & & 0.470 & & \\
\hline Education, years $\times$ Marital status & & & 0.823 & & \\
\hline Education, years $\times$ MMSE-NR & & & 0.514 & & \\
\hline Education, years $\times$ NPI-Q Agitation & & & 0.974 & & \\
\hline Education, years $\times$ NPI-Q Psychosis & & & 0.565 & & \\
\hline Education, years $\times$ NPI-Q Affective & & & 0.215 & & \\
\hline \multicolumn{6}{|l|}{ Education, years $\times$ Diagnosis } \\
\hline SCI & & & 0.470 & & \\
\hline MCI & & & 0.522 & & \\
\hline Other ${ }^{\mathrm{a}}$ & & & 0.841 & & \\
\hline Dementia - ref. & & & & & \\
\hline
\end{tabular}

All models included random effects for the single centres/clinics in each health region independent of type of clinic (geriatric/ psychiatric) to adjust for possible intra-centre correlations. None of the interactions considered were significant in the multivariate models. Italics indicate statistical significance. SE, standard error; ref., reference; MMSE-NR, sum score of the MiniMental State Examination, Norwegian revised version; NPI-Q, Neuropsychiatric Inventory Questionnaire; SCI, subjective cognitive impairment; MCI, mild cognitive impairment. ${ }^{a}$ Other diagnoses include depression, anxiety and psychotic diseases. 
Helvik et al.: Time from Symptom Debut to Dementia Assessment by the Specialist Healthcare Service in Norway

\section{Discussion}

This Norwegian study investigated the time from symptom debut to assessment for cognitive impairment at outpatient specialist healthcare clinics for dementia. The mean time from symptom debut to assessment for the total sample was $>2.5$ years. In people with a longer education, the time between the debut of symptoms and assessment was longer than in individuals with a shorter education. Furthermore, a higher agitation sub-syndrome score on the NPI-Q was associated with a longer duration between symptom debut and assessment. The duration from symptom debut to assessment was significantly longer in those who were diagnosed with dementia than in those with MCI.

In the present study, 5 more years of education was associated with an increase of $10 \%$ in the time from symptom debut to assessment when adjusted for other sociodemographic variables (age, gender and marital status), cognitive functioning, neuropsychiatric symptoms, receiving domiciliary care (yes/no), type of outpatient clinic visited and health region. The finding is a bit surprising since higher barriers for seeking help are typically reported for those with less education compared to individuals with higher education [44, 45]. Studies from the Netherlands and Italy did not find any association between amount of education and duration from symptom debut to diagnosis at a specialist outpatient clinic for dementia [29, 34]. A recent Chinese study found that people with a shorter education had a longer mean duration from symptom debut to assessment at a specialist outpatient clinic [18]. In the Chinese study, where the education level in older people may be lower than in Scandinavia and other parts of Europe, the researchers hypothesized that those who had very few years of education also had little knowledge about dementia and symptoms related to dementia. A comparison between cultures may be complicated due to cultural differences in how families deal with and compensate for dementia symptoms within the family.

In Norway, which has a generally high educational level, the association between years of education and longer duration to assessment may be understood according to the cognitive reserve theory. This means that despite brain pathology, some people are able to function quite well because of the structural and functional features of their brain [4-7]. Higher educational levels have been reported to increase a person's cognitive reserve capacity by fostering development of structural and functional brain structures and new cognitive strategies [6, 7]. Thus, in keeping with this, it may be possible that individuals with a longer education functioned better for a longer period than those with a shorter education. Consequently, people with a longer education and their next of kin may explain changes in cognitive functioning during the early phases of dementia as normal age-related cognitive decline rather than dementia. Furthermore, even if they suspect a cognitive pathology, the affected individuals and their next of kin may still delay seeking help as long as the individual's level of functioning remains quite good. We may speculate that the next of kin of those with a longer education are more resourceful and able to compensate for functional reduction for a longer time and, thus, experience the symptoms as less severe. Less severe symptoms may often delay a decision to seek help [15], which may be exacerbated by a fear of and stigmata related to dementia in society $[19,46]$. All of these factors may contribute to the delay in seeking help, especially when a person's functional level is quite good. However, if a person with less severe symptoms during the early phases of the disease chose to consult their general practitioner (GP), the dementia symptoms could be overlooked $[9,11,47]$. A referral to specialist care may be postponed until symptoms are more explicit/obvious [47].

A higher agitation sub-syndrome score on the NPI-Q at the assessment at a specialist healthcare clinic was associated with a longer duration from symptom debut to assessment compared to individuals with less severe symptoms. It is possible that the longer duration between symptom debut and assessment contributes to more severe neuropsychiatric 
symptoms, as these symptoms tend to become more common in later stages of dementia [48]. For our study, however, we do not have information about the process that brings an individual to specialist care or information about which symptoms were the main triggers for seeking assessment by the specialist care system. Other researchers have reported that the duration from symptom debut to consultation at a specialist healthcare clinic may be related to the individual or their next of kin as well as to the GP who was first consulted about symptoms [12,14, 49-51]. Often, the decision to seek medical help is taken by the next of kin or in cooperation with the individual with cognitive impairment. It has been reported that the degree of behavioural disturbance symptoms was often the trigger for next of kin to recognize symptoms as dementia related [52] and for seeking assessment [53]. Others have found that an accumulation of events or clues - other than, or in addition to, cognitive function - seems necessary for the next of kin to decide to seek assessment [37]. It may also be that the GP was consulted during an early phase of the disease, but that symptoms could have been misinterpreted or understood as stress, depression or other mental health problems and treated accordingly, or that the symptoms may have been overlooked until they became more explicit/ obvious [47].

The duration from symptom debut to assessment was significantly shorter for those who were subsequently diagnosed with MCI as compared to individuals with dementia. We do not have a firm explanation for this, but it may be related to how individuals are referred to specialist care. Healthcare in Scandinavia relies on the primary care physician, the GP, who addresses most health problems but refers patients to the specialist healthcare system when indicated [54]. Another explanation could be due to the level of insight, which is higher in patients with MCI than in those with dementia. When a dementia diagnosis is made by a GP, the specificity is almost $100 \%$, but GPs do not assess or diagnose every individual who is subsequently found to have dementia [11], and referral to the specialist healthcare is postponed $[9,47]$. Dementia assessments and referrals to the specialist care system are not simple mechanical processes but include a complex interaction between the person with symptoms, their next of kin and the GP. For example, the GP may refer people to specialist care if they or their next of kin insist [51]. In our study, we speculate that people who were later diagnosed with subjective cognitive impairment or MCI were referred because they or their next of kin were not satisfied with their GP consultation, or that their experience of the severity of symptoms led them to insist on an additional assessment by the specialist care system. Geographical location or the type of the outpatient specialist clinics to which patients were referred was not associated with the duration between symptom debut and first assessment.

An important limitation of all studies (including ours) that explore the duration from symptom debut to assessment or diagnosis is the retrospective estimation of the time of symptom onset, which alone could account for heterogeneous study outcomes [29]. The estimated time of symptom onset was based on the next of kin's recall and knowledge of symptoms of dementia. Because symptoms are usually not very noticeable at an early stage, the estimated time of symptom debut may not be accurate [18]. Information about when symptoms first appeared was missing in about half of the people in the NorCog register, and those who had been included in the study tended to be older with poorer cognitive function than those for whom information was missing. This weakens our study and our ability to draw firm conclusions. However, one of the strengths of our study is that we systematically asked for the time of symptom debut at the first assessment. It seems more likely that the recall bias may increase with an increase in the duration from assessment and diagnosis to when participants or next of kin are questioned about symptom debut [29].

We did not study the relationship between etiological diagnoses and duration from symptom debut to assessment. Instead, we explored the importance of subjective cognitive impairment, MCI and dementia. Nevertheless, we are aware that the type of dementia may 
Helvik et al.: Time from Symptom Debut to Dementia Assessment by the Specialist Healthcare Service in Norway

influence the duration. It is reported that people with frontotemporal dementia in general wait longer before having an assessment $[29,30]$. Due to poor statistical power (small diagnostic groups), we did not undertake this type of analysis.

Certain areas on which we lack information may influence the time from symptom debut to assessment by a specialist care clinic. Firstly, we do not know how referrals proceeded, meaning the process at the GP's and the specialist care service $[51,55]$. For example, the duration from the actual referral to the appointment for the assessment at the specialist care clinic was not available. Secondly, we do not have information about the quality or size of the individuals' social and family network, which may influence the accuracy of time for symptom debut and incentive to seek consultation. In this context, it would have been useful to have included data of the relatives' educational level in our analyses. However, such information is not available in NorCog. Thirdly, we do not know about each individual and their next of kin's general attitude towards and knowledge of cognitive impairment and dementia, if and how next of kin experience their caregiving burden related to their relative's symptoms, and who actually initiated the visit. Fourthly, we do not have systematic information about the progression of cognitive and neuropsychiatric symptoms from symptom debut to the assessment.

\section{Conclusion}

The duration from symptom debut to assessment for dementia was longer among those with a longer education. This may be because more highly educated people have a better ability to compensate for cognitive impairment, in line with the cognitive reserve hypothesis. However, the limitations of our study weaken our ability to draw firm conclusions, and there is a need to explore the association further.

\section{Disclosure Statement}

The authors declare that there are no conflicts of interest.

\section{References}

1 Wimo A, Jonsson L, Gustavsson A, McDaid D, Ersek K, Georges J, Gulacsi L, Karpati K, Kenigsberg P, Valtonen $\mathrm{H}$ : The economic impact of dementia in Europe in 2008 - cost estimates from the Eurocode project. Int J Geriatr Psychiatry 2011;26:825-832.

2 Vossius C, Selbæk G, Ydstebø A, Saltyte-Benth J, Godager G, Lurås H, Bergh S: Ressursbruk og sykdomsforløp ved demens (REDIC). 2015. https://www.fylkesmannen.no/Documents/Dokument\%20FMHE/04\%20 Helse\%20og\%20omsorg/Demenskonferanse/REDIC_rapport.pdf.

-3 Potkin SG: The ABC of Alzheimer's disease: ADL and improving day-to-day functioning of patients. Int Psychogeriatr 2002;14(suppl 1):7-26.

4 Stern Y: Cognitive reserve. Neuropsychologia 2009;47:2015-2028.

-5 Jones RN, Manly J, Glymour MM, Rentz DM, Jefferson AL, Stern Y: Conceptual and measurement challenges in research on cognitive reserve. J Int Neuropsychol Soc 2011;17:593-601.

-6 Lenehan ME, Summers MJ, Saunders NL, Summers JJ, Vickers JC: Relationship between education and agerelated cognitive decline: a review of recent research. Psychogeriatrics 2014, Epub ahead of print.

7 Chapko D, McCormack R, Black C, Staff R, Murray A: Life-course determinants of cognitive reserve (CR) in cognitive aging and dementia - a systematic literature review. Aging Ment Health 2017;1-12.

8 Lystrup LS, Lillesveen B, Nygard AM, Engedal K: (Public social health services to demented persons living at home in Norway). Tidsskr Nor Laegeforen 2006;126:1917-1920.

-9 Bradford A, Kunik ME, Schulz P, Williams SP, Singh H: Missed and delayed diagnosis of dementia in primary care: prevalence and contributing factors. Alzheimer Dis Assoc Disord 2009;23:306-314. 
$\$ 10$ Gelman CR: Learning from recruitment challenges: barriers to diagnosis, treatment, and research participation for Latinos with symptoms of Alzheimer's disease. J Gerontol Soc Work 2010;53:94-113.

11 van den Dungen P, van Marwijk HW, van der Horst HE, Moll van Charante EP, Macneil Vroomen J, van de Ven PM, van Hout HP: The accuracy of family physicians' dementia diagnoses at different stages of dementia: a systematic review. Int J Geriatr Psychiatry 2012;27:342-354.

$\checkmark 12$ Boise L, Morgan D, Kaye J, Camicioli R: Delays in the diagnosis of dementia: perspectives of family caregivers. Am J Alzheimers Dis 1999;14:20-26.

13 Speechly CM, Bridges-Webb C, Passmore E: The pathway to dementia diagnosis. Med J Aust 2008;189:487489.

14 Carpentier N, Bernard P, Grenier A, Guberman N: Using the life course perspective to study the entry into the illness trajectory: the perspective of caregivers of people with Alzheimer's disease. Soc Sci Med 2010;70: 1501-1508.

15 Prohaska TR, Keller ML, Leventhal EA, Leventhal H: Impact of symptoms and aging attribution on emotions and coping. Health Psychol 1987;6:495-514.

16 Ross GW, Abbott RD, Petrovitch H, Masaki KH, Murdaugh C, Trockman C, Curb JD, White LR: Frequency and characteristics of silent dementia among elderly Japanese-American men. The Honolulu-Asia Aging Study. JAMA 1997;277:800-805.

-17 Mahoney DF, Cloutterbuck J, Neary S, Zhan L: African American, Chinese, and Latino family caregivers' impressions of the onset and diagnosis of dementia: cross-cultural similarities and differences. Gerontologist 2005; 45:783-792.

18 Zhao M, Lv X, Tuerxun M, He J, Luo B, Chen W, Wang K, Gu P, Kuang W, Zhou Y, Qu Q, He J, Zhang N, Feng Y, Wang Y, Yu X, Wang H: Delayed help seeking behavior in dementia care: preliminary findings from the Clinical Pathway for Alzheimer's Disease in China (CPAD) study. Int Psychogeriatr 2016;28:211-219.

19 Brunet MD, McCartney M, Heath I, Tomlinson J, Gordon P, Cosgrove J, Deveson P, Gordon S, Marciano SA, Colvin D, Sayer M, Silverman R, Bhattia N: There is no evidence base for proposed dementia screening. BMJ 2012; 345:e8588.

20 Clement S, Schauman 0, Graham T, Maggioni F, Evans-Lacko S, Bezborodovs N, Morgan C, Rusch N, Brown JS, Thornicroft G: What is the impact of mental health-related stigma on help-seeking? A systematic review of quantitative and qualitative studies. Psychol Med 2015;45:11-27.

-21 Robinson L, Tang E, Taylor JP: Dementia: timely diagnosis and early intervention. BMJ 2015;350:h3029.

22 Howard R, McShane R, Lindesay J, Ritchie C, Baldwin A, Barber R, Burns A, Dening T, Findlay D, Holmes C, Hughes A, Jacoby R, Jones R, Jones R, McKeith I, Macharouthu A, O’Brien J, Passmore P, Sheehan B, Juszczak E, Katona C, Hills R, Knapp M, Ballard C, Brown R, Banerjee S, Onions C, Griffin M, Adams J, Gray R, Johnson T, Bentham P, Phillips P: Donepezil and memantine for moderate-to-severe Alzheimer's disease. N Engl J Med 2012;366:893-903.

-23 Livingston G, Kelly L, Lewis-Holmes E, Baio G, Morris S, Patel N, Omar RZ, Katona C, Cooper C: Non-pharmacological interventions for agitation in dementia: systematic review of randomised controlled trials. $\mathrm{Br} \mathrm{J}$ Psychiatry 2014;205:436-442.

24 Banerjee S, Wittenberg R: Clinical and cost effectiveness of services for early diagnosis and intervention in dementia. Int J Geriatr Psychiatry 2009;24:748-754.

-25 Wilkinson D, Stave C, Keohane D, Vincenzino 0: The role of general practitioners in the diagnosis and treatment of Alzheimer's disease: a multinational survey. J Int Med Res 2004;32:149-159.

-26 Knopman D, Donohue JA, Gutterman EM: Patterns of care in the early stages of Alzheimer's disease: impediments to timely diagnosis. J Am Geriatr Soc 2000;48:300-304.

27 Wackerbarth SB, Johnson MM: The carrot and the stick: benefits and barriers in getting a diagnosis. Alzheimer Dis Assoc Disord 2002;16:213-220.

28 Fiske A, Gatz M, Aadnoy B, Pedersen NL: Assessing age of dementia onset: validity of informant reports. Alzheimer Dis Assoc Disord 2005;19:128-134.

-29 van Vliet D, de Vugt ME, Bakker C, Pijnenburg YA, Vernooij-Dassen MJ, Koopmans RT, Verhey FR: Time to diagnosis in young-onset dementia as compared with late-onset dementia. Psychol Med 2013;43:423-432.

-30 Rosness TA, Haugen PK, Passant U, Engedal K: Frontotemporal dementia: a clinically complex diagnosis. Int J Geriatr Psychiatry 2008;23:837-842.

-31 Tijhuis MA, Peters L, Foets M: An orientation toward help-seeking for emotional problems. Soc Sci Med 1990; 31:989-995.

-32 Mackenzie CS, Gekoski WL, Knox VJ: Age, gender, and the underutilization of mental health services: the influence of help-seeking attitudes. Aging Ment Health 2006;10:574-582.

33 Galdas PM, Cheater F, Marshall P: Men and health help-seeking behaviour: literature review. J Adv Nurs 2005; 49:616-623.

34 Cattel C, Gambassi G, Sgadari A, Zuccala G, Carbonin P, Bernabei R: Correlates of delayed referral for the diagnosis of dementia in an outpatient population. J Gerontol A Biol Sci Med Sci 2000;55:M98-M102.

35 van Vliet D, de Vugt ME, Bakker C, Koopmans RT, Pijnenburg YA, Vernooij-Dassen MJ, Verhey FR: Caregivers' perspectives on the pre-diagnostic period in early onset dementia: a long and winding road. Int Psychogeriatr 2011;23:1393-1404.

36 Cameron L, Leventhal EA, Leventhal H: Symptom representations and affect as determinants of care seeking in a community-dwelling, adult sample population. Health Psychol 1993;12:171-179. 
Helvik et al.: Time from Symptom Debut to Dementia Assessment by the Specialist Healthcare Service in Norway

-37 Streams ME, Wackerbarth SB, Maxwell A: Diagnosis-seeking at subspecialty memory clinics: trigger events. Int J Geriatr Psychiatry 2003;18:915-924.

-38 Braekhus A, Ulstein I, Wyller TB, Engedal K: The Memory Clinic - outpatient assessment when dementia is suspected. Tidsskr Nor Laegeforen 2011;131:2254-2257.

-39 Folstein MF, Folstein SE, McHugh PR: "Mini-mental state." A practical method for grading the cognitive state of patients for the clinician. J Psychiatr Res 1975;12:189-198.

-40 Engedal K, Haugen P, Gilje K, Laake P: Efficacy of short mental tests in the detection of mental impairment in old age. Compr Gerontol A 1988;2:87-93.

41 Kaufer DI, Cummings JL, Ketchel P, Smith V, MacMillan A, Shelley T, Lopez OL, DeKosky ST: Validation of the NPI-Q, a brief clinical form of the Neuropsychiatric Inventory. J Neuropsychiatry Clin Neurosci 2000;12:233239.

42 Selbaek G, Kirkevold O, Sommer OH, Engedal K: The reliability and validity of the Norwegian version of the Neuropsychiatric Inventory, nursing home version (NPI-NH). Int Psychogeriatr 2008;20:375-382.

43 Wergeland JN, Selbaek G, Bergh S, Soederhamn U, Kirkevold O: Predictors for nursing home admission and death among community-dwelling people 70 years and older who receive domiciliary care. Dement Geriatr Cogn Disord Extra 2015;5:320-329.

44 Pires C, Silva D, Maroco J, Gino S, Mendes T, Schmand BA, Guerreiro M, de Mendonca A: Memory complaints associated with seeking clinical care. Int J Alzheimers Dis 2012;2012:725329.

45 Hodgson L, Cutler S: Help seeking for personal concerns about developing Alzheimer's disease. J Appl Gerontol 2004;24:385-410.

46 Phillipson L, Magee CA, Jones SC, Skladzien E: Correlates of dementia attitudes in a sample of middle-aged Australian adults. Australas J Ageing 2014;33:158-163.

47 Johannessen A, Helvik AS, Engedal K, Thorsen K: Experiences and needs of spouses of persons with youngonset frontotemporal lobe dementia during the progression of the disease. Scand J Caring Sci 2017;31:779788.

48 Stella F, Laks J, Govone JS, de Medeiros K, Forlenza OV: Association of neuropsychiatric syndromes with global clinical deterioration in Alzheimer's disease patients. Int Psychogeriatr 2016;28:779-786.

49 Connell CM, Gallant MP: Spouse caregivers' attitudes toward obtaining a diagnosis of a dementing illness. J Am Geriatr Soc 1996;44:1003-1009.

50 De Lepeleire J, Heyman J, Buntinx F: The early diagnosis of dementia: triggers, early signs and luxating events. Fam Pract 1998;15:431-436.

51 Thorsen 0, Hartveit M, Baerheim A: General practitioners' reflections on referring: an asymmetric or nondialogical process? Scand J Prim Health Care 2012;30:241-246.

52 Eustace A, Bruce I, Coen R, Cunningham C, Walsh C, Walsh JB, Coakley D, Lawlor BA: Behavioural disturbance triggers recognition of dementia by family informants. Int J Geriatr Psychiatry 2007;22:574-579.

53 Chenoweth B, Spencer B: Dementia: the experience of family caregivers. Gerontologist 1986;26:267-272.

54 Helsedirektoratet: Nasjonal veileder for henvisninger til specialisthelsetjenesten (National guideline for referral to the specialist health care service). 2015. https://helsedirektoratet.no/retningslinjer/henvisningsveileder.

55 Thorsen 0, Hartveit M, Baerheim A: The consultants' role in the referring process with general practitioners: partners or adjudicators? A qualitative study. BMC Fam Pract 2013;14:153. 